\title{
The Induction of Apoptosis by Methotrexate in Activated Lymphocytes as Indicated by Fluorescence Hyperpolarization: a Possible Model for Predicting Methotrexate Therapy for Rheumatoid Arthritis Patients
}

\author{
Shoshy Herman ${ }^{1}$, Naomi Zurgil ${ }^{1}$, Pnina Langevitz², Michael Ehrenfeld ${ }^{2}$, and Mordechai Deutsch ${ }^{*}$ \\ ${ }^{1}$ The Biophysical Interdisciplinary Schottenstein Center for the Research and the Technology of the Cellome, \\ Physics Department, Bar-Ilan University, Ramat-Gan 52900 Israel and ${ }^{2}$ Tel Hashomer, Department of \\ Rheumatology, Sheba Medical Center, Tel Hashomer, Israel
}

\begin{abstract}
The objectives of this study were to test the in vitro response of healthy non-activated, activated, and rheumatoid arthritis (RA) lymphocytes to methotrexate (MTX), and design an in vitro model for predicting the efficiency of MTX treatment for RA patients. Considering the RA profile of clonal-expanded $\mathrm{CD4}^{+} \mathrm{T}$ cells, phytohemagglutinin-activated mononuclear cells taken from healthy donors were incubated with different concentrations of MTX. The MTX-immunosuppressive effect was tested by fluorescence intensity measurements, including PI assay and annexin V assay. For simple detection, we used the Individual Cell Scanner (IC-S), which enables the measurement of early events in individual cells. Healthy mononuclear cells (MNC), and MNC derived from RA patients, were tested by the IC-S while utilizing fluorescence polarization (FP) measurements of fluorescein diacetate (FDA) as an established marker of activation or suppression. In healthy activated MNC, we found that MTX, through its early incubation period, interferes with the activation signal obtained by PHA and exerts an apoptotic signal, which is noted by increases in the FP. Comparing our model to six long-standing RA patients and five newly-diagnosed patients revealed significant differences in the FP measurements, including fluorescence depolarization as an early established measurement of lymphocyte activation, and hyperpolarization as a measurement of an early immunosuppressive effect. We conclude that MTX, an effective therapy for RA patients, could easily be tested by fluorescence polarization measurements of FDA before (or during) clinical use in order to predict its efficiency on a specific RA patient. Moreover, the FP measurements can be used for the diagnosis, and making timing and dosage decisions.
\end{abstract}

Key words: Rheumatoid Arthritis (RA)/Methotrexate (MTX)/Individual Cell Scanner (IC-S)/Mononuclear Cells (MNC)/ Fluorescence Polarization (FP)

Methotrexate (MTX), a systemic chemotherapeutic agent originally used for malignant disorders (Jackson et al., 1984), is presently being used to treat inflammatory disorders as well (Willkens et al., 1984). MTX was found to be the preferred drug for patients suffering from rheumatoid

*To whom correspondence should be addressed: Mordechai Deutsch, Ph.D., The Biophysical Interdisciplinary Center for the Research and the Technology of the Cellome and The Schottenstein Center for Early Detection of Cancer, Physics Department, Bar-Ilan University, Ramat-Gan 52900, ISRAEL.

Tel: +972-3-5344675, 5318349, 5354148, Fax: +972-3-5342019

E-mail: rtcellom@mail.biu.ac.il

Abbreviations: RA, rheumatoid arthritis; MTX, methotrexate; IC-S, Individual Cell Scanner; MNC, mononuclear cells; FDA, fluorescein diacetate; FP, fluorescence polarization; PHA, phytohaemagglutinin; PI, propidium iodide; AICAribotide, 5-amino-4-imidazolecarboxamideriboside-5'-monophosphate. arthritis (RA) (Weinblatt et al., 1985; Wolfe et al., 1990). While in chemotherapy MTX doses are definitely high (up to $30 \mu \mathrm{g} / \mathrm{m}^{2}$ ), in autoimmune diseases a low MTX dose of $7-15 \mathrm{mg} /$ week was found to be effective.

It has been realized over the past decade that early diagnosis and early treatment are critical for RA patients. Moreover, an overall plateau of clinical response to MTX is reached after only six months of treatment. Therefore, enabling patients with early arthritis to access the appropriate therapy is of great importance. Additionally, because the last decade has seen many RA patients who failed to respond to the MTX drug, the availability of new options could bring more optimal care to them. Therefore, we find it necessary to predict the immunosuppressive effects of MTX. 
So far, the following findings have been cited to explain MTX's immunosuppressive and anti-inflammatory properties at the cellular level:

a) MTX inhibits folate-dependent enzymes via polyglutamated derivatives, which leads to anti-proliferation (Chabner et al., 1985; Sperling et al., 1990; Fairbanks et al., 1999). The inhibition by MTX of the folate dependent enzyme 5-amino-4-imidazolecarboxamide-riboside-5'-monophosphate (AICAribotide) transformylase can lead to the intracellular accumulation of AICAribotide, as demonstrated with an in vivo model of inflammation (Cronstein et al., 1993).

b) MTX mediates the release of adenosine, which suppresses inflammation (Cronstein et al., 1991). Subsequent studies implicated adenine nucleotides, released as a result of cellular injury or necrosis, as being the source of the extracellular adenosine, in which AICAribotide might be involved indirectly (Morabito et al., 1998).

c) Recently, it was proposed by Genestier et al. that the immunosuppressive properties of MTX relate to the induction of apoptosis, especially in activated T cells (Genestier et al., 1998; Nishioka et al., 1998).

Surprisingly, MTX in normal in vitro mononuclear cells has received little attention. Genestier et $a l$. were the first to demonstrate that apoptosis of activated, healthy T-cells by MTX does occur, and probably does not require the interaction between CD95 (FAS, APO-1) and its ligand. In addition, adenosine release by these cells could account for only a small part of MTX activity (Genestier et al., 1998). An additional single study concentrates on MTX suppressive effect in mitogen stimulated healthy T-lymphocytes, and suggests that MTX inhibits the first committed step of purine biosynthesis (Fairbanks et al., 1999). Both of the latter reports suggest that apoptosis by MTX requires progression of activated T-cells to the S-phase of the cell cycle, as evidenced by drug or antibody interference with IL-2 synthesis or signaling pathway.

Considerable evidence suggests that the cell subpopulation T-helper 1 (Th1) plays a predominant role in RA pathogenesis. Lymphocytes obtained from RA patients produce Th1 type cytokines (Singh et al., 1999; Kusaba et al., 1998). Cytokines produced by Th cells are of critical importance for the disease development or subsiding (Infante-Durate and Kamradt, 1999). Rudwaleit et al. report on in vivo immunosuppressive effect of MTX, manifested by a decrease in TNF $\alpha$ production and an increase in IL-10 production (Rudwaleit et al., 2000), suggesting MTX involvement in a cellular regulatory mechanism relevant to the disease remission. Another study evaluates the influence of long term therapy by MTX on the general normalization of the cytokine balance (Th1/Th2) in both $\mathrm{CD}^{+}$and $\mathrm{CD}^{+}$ lymphocytes (Schuerwegh et al., 2001).

The clonal expansion of $\mathrm{CD}^{+}{ }^{+} \mathrm{T}$ cells is a characteristic finding in patients with RA (Goronzy et al., 1994). Expanded $\mathrm{CD}^{+}$clones are present in the blood and in- filtrate into the joint, persisting for years (Waase et al., 1996; Schmidt et al., 1996). Based on the latter report (Genestier et al., 1998) and our earlier findings, which indicated that lymphocyte activation as well as apoptosis can be monitored and measured by fluorescence polarization (FP) of FDA-labeled cells using the Individual Cell Scanner (IC-S) (Zurgil et al., 2000; Zurgil et al., 1999a; Deutsch et al., 2000a), we designed this study to test the effects of MTX on activated lymphocytes.

Fluorescence polarization is considered to be one of the first functional cytometric parameters (Shapiro, 1995). It was initially suggested by the Cerceks as an indicator of lymphocyte activation following the incubation of the lymphocytes with phytohemagglutinin (PHA) (Cercek and Cercek, 1977), a finding that was later verified by others as well (Kaplan et al., 1997; Orjasaeter et al., 1979; Schnuda, 1980; Pritchard et al., 1982; Rolland et al., 1984; Sakamoto et al., 1981).

In the present study, an in vitro model was designed to find the most suitable suppression effect of MTX on activated lymphocytes. The IC-S was used to monitor the development of the apoptotic process, following MTX administration, in an effort to establish an early event that demonstrates the MTX suppression effect. This model may help RA patients to receive the appropriate treatment, as well as to predict dosage and timing for better disease therapy.

\section{Materials and Methods}

\section{Materials}

Propidium iodide (PI), MTX, RNase, and trypan blue (TB) were obtained from Sigma (St. Louis, MO, USA). Fluorescein diacetate (FDA) was obtained from Riedle de Haen AG (Seize, Germany). Working dilutions $(1.2 \mu \mathrm{M}$ in phosphate buffered saline (PBS)) were prepared from a $25 \mathrm{mM}$ stock solution in acetic acid (Frutarom, Israel). Ficoll-Paque was obtained from Pharmacia LKB, Sweden. Dulbecco's PBS containing $1.3 \mathrm{mM} \mathrm{Ca}^{2+}$ and $0.5 \mathrm{mM}$ $\mathrm{Mg}^{2+}$ and RPMI 1640 were obtained from Biological Industries (Beit Haemek, Israel). Phytohaemagglutinin (PHA, Wellcome, UK) was dissolved in PBS $(0.9 \mathrm{mg} / \mathrm{ml})$ and stored at $-20^{\circ} \mathrm{C}$.

\section{Cell preparation}

In this study were included 11 RA patients and 18 healthy volunteers. The RA patients were diagnosed according to the ACR criteria (Arnett et al., 1988). The RA patient group included 6 RA patients ( 2 males and 4 females) treated by weekly oral administration of MTX (10 mg in 2 patients and $12.5 \mathrm{mg}$ in 4 patients), and 5 recently diagnosed untreated RA patients ( 1 male and 4 females). The average age of the patients was 61 (ranging 34-81). All healthy volunteers had no history of any chronic disorders. The research was certified and conducted at the Sheba Medical Center, Tel Hashomer, Israel, under the Helsinki regulations. The study 
participants gave their informed consent to donate $10 \mathrm{ml}$ blood for examination.

Mononuclear cells (MNC) were isolated from healthy and RA peripheral blood using the Ficoll Paque procedure, as previously described (Kaplan et al., 1997). Following separation, the cells were washed, twice in saline and once in PBS, and then suspended in enriched RPMI at a concentration of $1.5 \times 10^{6}$ cells $/ \mathrm{ml}$. Viability was checked by analyzing the ability to exclude TB by light microscope. PHA stimulation of MNC was performed by adding a final optimal concentration of $5 \mu \mathrm{g} / \mathrm{ml}$ PHA to $\mathrm{MNC}$ for different incubation periods and incubating at $37^{\circ} \mathrm{C}, 5 \% \mathrm{CO}_{2}$.

\section{PI assay}

Following treatment, $1.5 \times 10^{6}$ cells $/ \mathrm{ml}$ were washed with PBS and stained with PI at a final concentration of $1 \mu \mathrm{g} / \mathrm{ml}$. Fluorescent cells were counted under a fluorescence microscope.

\section{Annexin V assay}

One million cells were washed with PBS and resuspended in binding buffer (Genzyme, Cambridge, MA). FITC-annexin V was added to a final concentration of $1 \mu \mathrm{g} / \mathrm{ml}$, while PI was simultaneously introduced. After $10 \mathrm{~min}$ of incubation in the dark at room temperature, the cells were analyzed by flow cytometry (FACScan BD).

\section{Determination of apoptosis by measuring cell cycle status}

In order to assess cell cycle and apoptosis, $1 \times 10^{6}$ cells were resuspended with $70 \%$ cold ethanol. Cells were settled by centrifugation and resuspended with $1 \mathrm{ml}$ lysing buffer containing $40 \mu \mathrm{g} / \mathrm{ml}$ RNase A. They were then stained with $100 \mu \mathrm{g} / \mathrm{ml}$ PI and stored in the dark at $4^{\circ} \mathrm{C}$ for at least $30 \mathrm{~min}$ before FACS analysis. A total of 20,000 events were acquired with a FACScan (Becton Dickinson). Gates for apoptotic cells appeared to the left of the $\mathrm{G}_{0} / \mathrm{G}_{1}$ peak.

\section{FDA staining}

Treated or untreated cells were washed 3 times with incomplete RPMI 1640 medium, which lacked phenol red but contained 10 $\mu \mathrm{M}$ HEPES buffer solution. An aliquot of $50 \mu \mathrm{l}$ of cell suspension $\left(1.5 \times 10^{6} \mathrm{ml}\right)$ was added to $50 \mu \mathrm{l}$ FDA staining solution in PBS and incubated at room temperature for $5 \mathrm{~min}$. At the end of incubation, the cells were settled in their traps on the cell carrier, as previously described (Deutsch and Weinreb, 1994), washed 3 times with fresh buffer in order to remove excess staining solution, and measured for fluorescence polarization (FP). The FP is defined as the ratio $\left(\mathrm{FI}_{\mathrm{II}}-\mathrm{FI}_{+}\right) /\left(\mathrm{FI}_{\mathrm{II}}+\mathrm{FI}_{+}\right)$, where (II) and (+) correspond to the FI measured parallel and perpendicular to the excitation field vector, respectively. The more the molecule rotational movement is restricted, the higher the FP value and vice versa. The FP is dependent on intrinsic molecular variables such as fluorescence lifetime and the moment of inertia, as well as on micro-environmental parameters of the media hosting the fluorophore probe, including viscosity and temperature.
FP is a powerful and sensitive technique for the study of macromolecular interactions, conformational changes, membrane fluidity, and cytoplasmic viscosity (Zurgil et al., 1999b; Gidwani et al., 2001; Dandliker and Feigen, 1961; Levison et al., 1976; Jolley, 1996). The IC-S is a multiparametric multilaser-based static cytometer. It enables precise repeated measurements on selected individual cells within a population under changeable physiological conditions. On-line reagent addition or changes in the experimental conditions (i.e., addition of apoptosis inducers or inhibitors, a change of buffers) can be accomplished, and dynamic changes on given individual cells are followed in real time. Principal approaches of the IC-S methodology were published elsewhere (Deutsch and Weinreb, 1994).

\section{IC-S apparatus}

The IC-S apparatus was previously described in detail (Deutsch $e t$ al., 2000a; Sunray et al., 1999). In short, it is a multiparametric, computerized, discrete static cytometer, which was designed, built, and upgraded in our labs. Its central feature is the cell tray (CT), a microsieve incorporating a two-dimensional trap array with $20 \mu \mathrm{m}$ pitched holes, each having an effective opening diameter of $7 \mu \mathrm{m}$ and about $8 \mu \mathrm{m}$ depth, in which individual cells are placed. The $\mathrm{CT}$ is mounted on a computer-controlled stage that enables repeated multi-scanning of the same cells.

In the present study, cells were irradiated with $1-10 \mu \mathrm{W}$ of 442 $\mathrm{nm}$ light from a He-Cd laser. Under the staining conditions used here, the sampling time for obtaining a count of 10,000 photons from each dye-loaded cell varied from $0.001 \mathrm{sec}$ to approximately $0.5 \mathrm{sec}$.

The acquired data, including cell position, measurement duration for each cell, absolute time, intensity at two different wavelengths, computed polarization values, and test set-up information, are displayed on the screen, on-line, graphically and numerically, and stored in the memory. Software enables the determination of the range and other statistical characteristics of all parameters, either for the entire cell population or for an operator-selected sub-population before or during the scan.

\section{Statistical analysis}

Data, expressed as mean $\pm \mathrm{SD}$, was analyzed by a two-tailed paired Student's t test. Differences were determined to be significant for $\mathrm{P} \leq 0.05$.

\section{Results}

\section{MTX induces an apoptotic effect on mitogen-activated MNC after $72 \mathrm{~h}$}

In order to emulate the RA MNC picture and further investigate the best potential effect of MTX on activated human $\mathrm{MNC}$, the cells were incubated with PHA $(5 \mu \mathrm{g} / \mathrm{ml})$ for 24 , 48, 72, and $96 \mathrm{~h}$ and then suppressed by MTX for $24 \mathrm{~h}$ (Fig. 1a). MTX concentrations ranging from $0.01-10 \mu \mathrm{M}$ were tested, reproducing the low-dose therapy currently given to 
RA patients. The optimal doses were found to be $0.1 \mu \mathrm{M}$ and $1 \mu \mathrm{M}$. Cell death was demonstrated through the PI exclusion assay and cell viability, by the exclusion of TB. A time-dependent effect of suppression was noted with all doses of MTX (Fig. 1a). However, $96 \mathrm{~h}$ of proliferation was

(a)

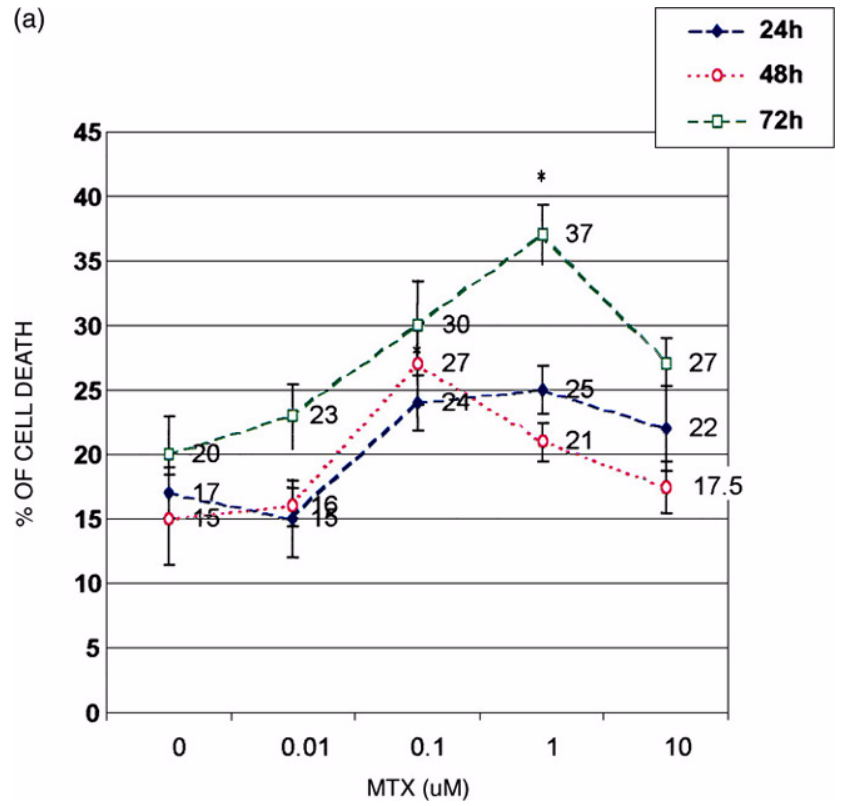

(b)

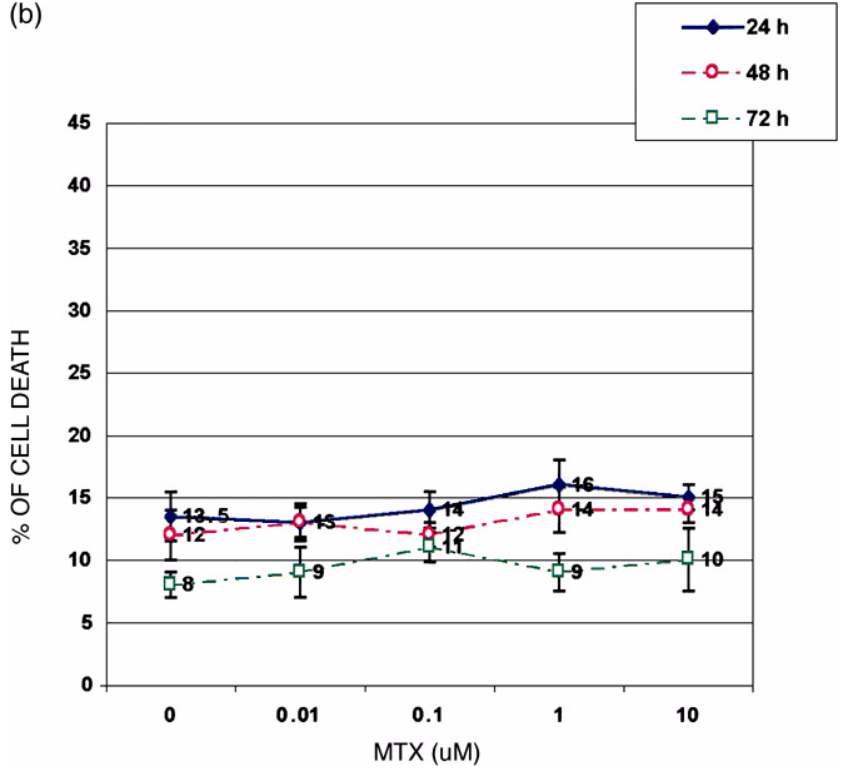

Fig. 1. (a) Percentage of cell death by MTX administration. MNC $\left(1.5 \times 10^{6}\right)$ stimulated with PHA $(5 \mu \mathrm{g} / \mathrm{ml})$ for 24,48 , and $72 \mathrm{~h}$, followed by incubation with different MTX concentrations $(0.01-10 \mu \mathrm{M})$ for an additional $24 \mathrm{~h}$. Results represent mean $\pm \mathrm{SE}$ of 3 different experiments. ${ }^{*}=\mathrm{P} \leq 0.05$. (b) Unstimulated MNC for 24,48 , and $72 \mathrm{~h}$, incubated with different MTX concentrations $(0.01-10 \mu \mathrm{M})$ for an additional $24 \mathrm{~h}$. Results represent mean $\pm \mathrm{SE}$ of 3 different experiments. not sufficient to exert a significant suppression effect by MTX (data not shown). A remarkably significant increase in apoptotic cells (37\%) resulted from $72 \mathrm{~h}$ of PHA activation followed by suppression with $1 \mu \mathrm{M}$ MTX, as compared to $20 \%$ cell death in the absence of MTX (Fig. 1a). Moreover, testing all the doses at all examined time periods in the absence of PHA pre-stimulation indicated that MTX alone barely enhanced the apoptotic rate (Fig. 1b). During all stimulation times, a progressive decrease in cell viability was evident, which reflects the nature of proliferated cells. The most significant decrease was noted at $72 \mathrm{~h}$ of PHA stimulation (Fig. 2). This concurs with data in which $72 \mathrm{~h}$ of PHA stimulation followed by $1 \mu \mathrm{M}$ MTX incubation enhanced the percentage of cell death. Ten $\mu \mathrm{M}$ MTX was found to be toxic for cell cultures (Fig. 2).

These data indicate that MTX inhibits cell proliferation and induces effective cell death of highly activated lymphocytes. Alternatively, at short proliferation signals $(24 \mathrm{~h})$, MTX yields a low decrease of viable cell counts. In order to confirm our data for the apoptotic process, two other tests were executed parallel to the PI test: cell cycle analysis for the pre $G_{1}$ event and the annexin $V$ assay. The results show a pattern similar to the one described above. Incidence of apoptosis was substantially greater after pre-incubation of MNC with PHA for $72 \mathrm{~h}$ followed by suppression with MTX for another $24 \mathrm{~h}$. The cell counts at the pre $\mathrm{G}_{1}$ state were found to be $21.7 \%$ (Fig. 3a), as compared to cells suppressed by MTX alone, which yielded a count of $7.26 \%$ (Fig. 3b). Cells incubated with PHA alone for $72 \mathrm{~h}$ yielded a count of $12.68 \%$ (Fig. 3c).

The annexin V assay is summarized in Table I. Early and

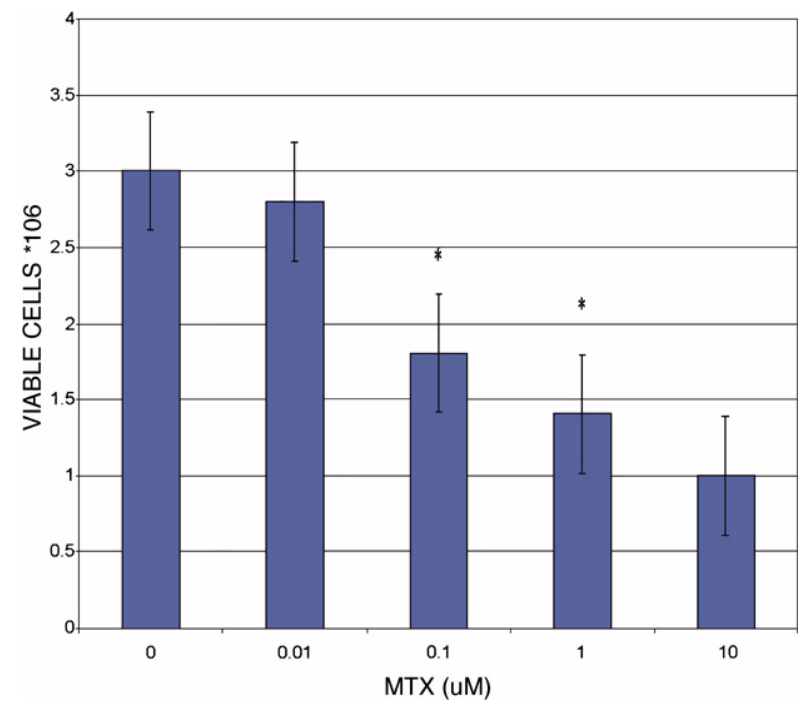

Fig. 2. The effect of MTX on cell viability. MNC $\left(1.5 \times 10^{6}\right)$ stimulated with PHA $(5 \mu \mathrm{g} / \mathrm{ml})$ for $72 \mathrm{~h}$, followed by $24 \mathrm{~h}$ incubation with $(0.01-10$ $\mu \mathrm{M})$ or without MTX. Results represent mean \pm SE of 3 different experiments. ${ }^{*}=\mathrm{P} \leq 0.05$. 
(a)

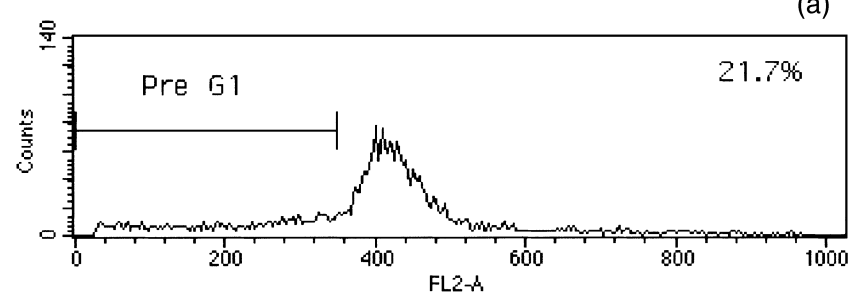

(b)

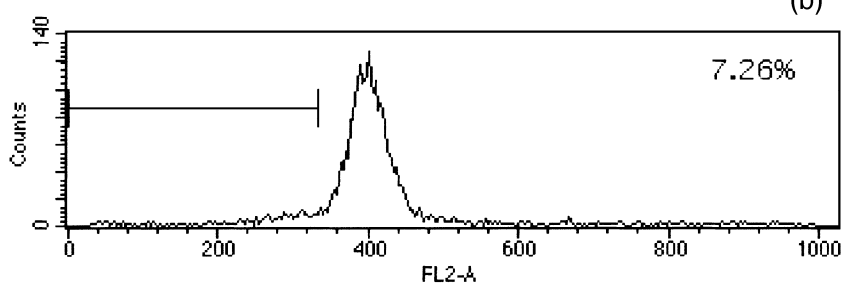

(c)

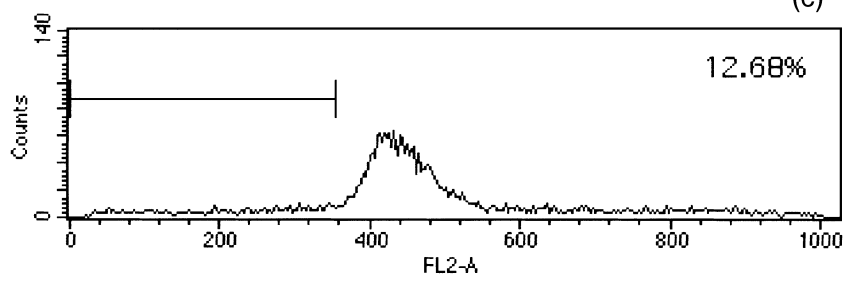

Fig. 3. Determination of pre-G1 phase of cell cycle by "FACS" analysis. (a) MNC pre-incubated with PHA $(5 \mu \mathrm{g} / \mathrm{ml})$ for $72 \mathrm{~h}$, followed by incubation with $1 \mu \mathrm{M}$ MTX.

(b) MNC incubated for $72 \mathrm{~h}$ without any stimuli, followed by incubation for $24 \mathrm{~h}$ with MTX $(1 \mu \mathrm{M})$ alone.

(c) MNC incubated for $96 \mathrm{~h}$ with PHA $(5 \mu \mathrm{g} / \mathrm{ml})$ alone.

late apoptosis were measured by double staining with PI and annexinV-Fitc. As seen, a significant count of $\left(8^{\mathrm{ANN}}+17^{\mathrm{ANN}+\mathrm{PI}}\right)$ was noted when $\mathrm{MNC}$ were pre-stimulated with PHA and then treated with MTX. Unstimulated MNC which were treated with MTX yielded an average percentage of events $\left(3.5^{\mathrm{ANN}}+7^{\mathrm{ANN}+\mathrm{PI}}\right)$, which was quite similar to PHA-stimulated cells which were not treated with MTX. Completely untreated MNC exhibited the lowest percentage of apoptotic events $\left(4^{\mathrm{ANN}}+4^{\mathrm{ANN}+\mathrm{PI}}\right)$.

\section{The IC-S Cytometer as a tool for monitoring MNC stimulation and suppression by FP measurements}

The IC-S apparatus was used to evaluate, assess, and build a new detecting and investigating model for inducing apoptosis in $72 \mathrm{~h}$ proliferated lymphocytes. It has previously been shown that lymphocyte activation involves early structural changes in cytoplasmic fluidity, which can easily be monitored by fluorescence depolarization of cells labeled with fluorescein diacetate (FDA) (Sunray et al., 1999; Deutsch et al., 2000b). The more restricted the fluorescent probe mobility, the higher its FP, which is indicated by probe size, hosting media viscosity, and binding. Further studies showed that the apoptotic event can be demonstrated by the increase in fluorescence polarization (FP) of FDA (Zurgil et $a l ., 2000)$. FDA FP measurements were used in this study to further analyze the in vitro response of activated lymphocytes to MTX.

Fig. 4 demonstrates a typical histogram distribution of FP values of FDA-labeled MNC that have been stimulated for $96 \mathrm{~h}$ with PHA, MTX, or a combination of both. As can be seen, unstimulated MNC, used as control cells (CON), yield a high mean FP value (0.187), while those treated with only PHA for $96 \mathrm{~h}$ exhibited the lowest mean value of FP. Interestingly, MNC treated with MTX alone during the last $24 \mathrm{~h}$ exhibited a pattern similar to that of untreated cells. Following treatment with PHA for $72 \mathrm{~h}$ and MTX during the last $24 \mathrm{~h}$, an intermediate mean FP value was obtained, indicating the occurrence of apoptosis, which, as discussed above, is manifested by hyperpolarization. Table II, which summarizes various experiments similar to the typical histogram discussed above, confirms the above data where a depolarization signal is evident following $72 \mathrm{~h}$ of PHA activation of normal MNC and hyperpolarization, which is maintained by MTX involvement.

Since intracellular fluorescein hyperpolarization was found to be an indicator of early apoptotic events (Zurgil et al., 2000), the next step was to trace early signals of the suppression of activation by MTX during its first hours of incubation via the IC-S. MTX $(1 \mu \mathrm{M})$ was added to MNC that had been activated for $72 \mathrm{~h}$ with PHA and immediately tested for FDA FP. FDA FP was measured during the first 3

Table I. ANNEXIN V ASSAY

\begin{tabular}{llcccc}
\hline & & $\begin{array}{c}\text { \% of events } \\
\text { Annexin }\end{array}$ & $\begin{array}{c}\text { \% of events } \\
\text { PIPOs }\end{array}$ & $\begin{array}{c}\text { \% of events } \\
\text { Annexin }{ }^{\text {POS }}+\mathrm{PI}^{\mathrm{POS}}\end{array}$ & $\begin{array}{c}\% \text { of events } \\
\text { Annexin }^{\mathrm{NEG}}+\mathrm{PI}^{\mathrm{NEG}}\end{array}$ \\
\hline 1 & Control & $4 \pm 0.4$ & $8 \pm 1.0$ & $4 \pm 0.8$ & $84 \pm 4.1$ \\
2 & PHA $(5 \mu \mathrm{g} / \mathrm{ml})$ & $3 \pm 0.5$ & $13 \pm 1.2$ & $8 \pm 0.3$ & $76 \pm 3.1$ \\
3 & MTX $(1 \mu \mathrm{M})$ & $3.5 \pm 0.2$ & $10 \pm 0.2$ & $7 \pm 0.9$ & $79.5 \pm 5.4$ \\
4 & PHA+MTX & $8 \pm 0.9^{*}$ & $10 \pm 0.5$ & $17 \pm 1.5^{*}$ & $65 \pm 3.2^{*}$ \\
\hline
\end{tabular}

Distinction between treated and untreated healthy MNC with both PHA and MTX. Results represent mean \pm SE of three different experiments. ${ }^{*}=\mathrm{p} \leq 0.05$. 


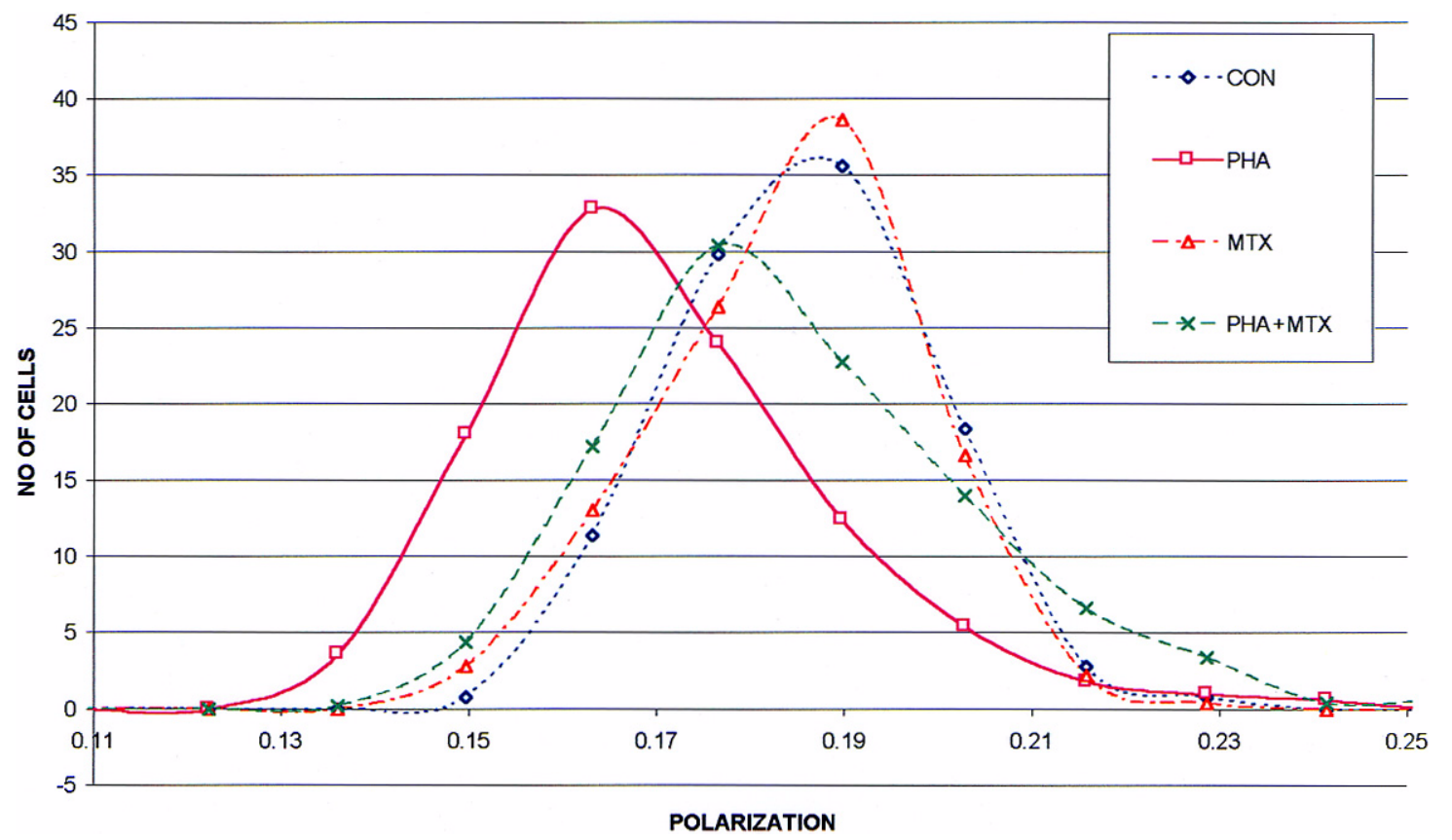

Fig. 4. A scatter histogram of the FP of FDA-labeled cells. MNC pre-incubated both with and without PHA for $72 \mathrm{~h}$, followed by suppression with (1 $\mu \mathrm{M})$ MTX for $24 \mathrm{~h}$.

Table II. The \% Change of FP VALues of FDA

\begin{tabular}{lcc}
\hline \multicolumn{1}{c}{ Treatment } & FP & \% of Change \\
\hline Control & $0.207 \pm 0.005$ & 0 \\
PHA $(5 \mu \mathrm{g} / \mathrm{ml})$ & $0.185 \pm 0.003^{*}$ & 11 \\
$\operatorname{MTX}(1 \mu \mathrm{M})$ & $0.196 \pm 0.007$ & 5.5 \\
PHA+MTX & $0.191 \pm 0.006^{*}$ & 8 \\
\hline
\end{tabular}

The $\%$ change of FP values of FDA, measured using $\left(1.5 \times 10^{6}\right)$ cells stimulated either by PHA or MTX or by a combination of both. Results represent mean $\pm \mathrm{SE}$ of three different experiments.

$*=\mathrm{p} \leq 0.05$.

h of MTX addition. Fig. 5 shows that the hyperpolarization signal was evident and more significant during the second hour of MTX incubation (15\%), as compared to only $6.5 \%$ during the third hour, with a continuous moderate decrease over $24 \mathrm{~h}$ of suppression.

\section{Polarization measurements of MNC derived from $R A$ patients}

Finally, the question arose as to the capability of the IC-S to recognize the apoptotic signal triggered by MTX in MNC obtained from RA patients (via FDA FP measurements). For this purpose, six RA patients treated with MTX (10$12.5 \mathrm{mg} /$ week) were tested. All of them exhibited low FP values indicating their activation status (Table III), a result similar to that obtained in normal PHA-activated lympho-

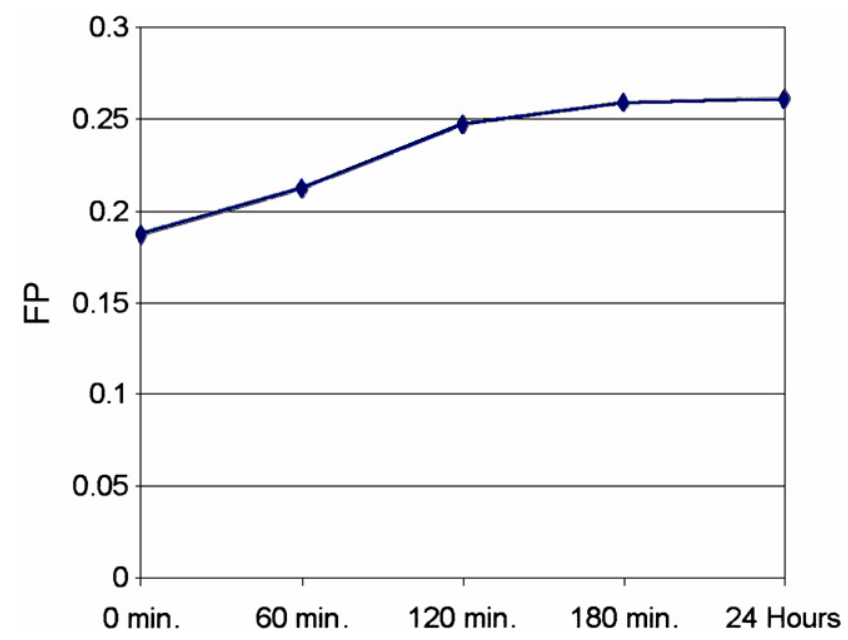

Fig. 5. Hyperpolarization time-dependency of PHA-activated cells treated with MTX. MNC $\left(1.5 \times 10^{6}\right)$ activated with PHA $(5 \mu \mathrm{g} / \mathrm{ml})$ for $72 \mathrm{~h}$, followed by simultaneous FDA staining and MTX administration.

cytes. In vitro exposure of RA lymphocytes to MTX $(1 \mu \mathrm{M})$ for $24 \mathrm{~h}$ yielded an increase in the FP values of the cells, meaning an apoptotic effect by MTX was noticed.

Five newly-diagnosed, but not yet treated, RA patients exhibited a high FP value (average FP of 0.202) (Table III), which was significantly depolarized in 4 of these patients by the in vitro addition of PHA and MTX. The polarization rate of the fifth patient remained the same, a pattern that will be 
Table III. FP VALUES OF FDA

\begin{tabular}{ll}
\hline $\begin{array}{l}\text { In vitro treatment for RA } \\
\text { patients recently diagnosed }\end{array}$ & FP Values \\
\hline Control & $0.202 \pm 0.003$ \\
PHA+MTX & $\mathbf{0 . 1 8 6} \pm \mathbf{0 . 0 0 4}$ \\
PHA & $0.190 \pm 0.002$ \\
MTX & $0.199 \pm 0.004$ \\
\hline $\begin{array}{l}\text { In vitro treatment for RA } \\
\text { patients clinically treated } \\
\text { with MTX }\end{array}$ \\
\hline $\begin{array}{l}\text { Control } \\
\text { MTX }\end{array}$ \\
\hline
\end{tabular}

The $\%$ change of FP values of FDA, measured using $\left(1.5 \times 10^{6}\right)$ cells stimulated either by PHA or MTX or by a combination of both. Results represent mean $\pm \mathrm{SE}$ of three different experiments.

${ }^{*}=\mathrm{p} \leq 0.05$.

discussed further. The in vitro exposure of these MNC to PHA alone considerably decreased their FP value, meaning that the MNC were not fully activated. Notably, the in vitro addition of MTX alone did not affect the FP value.

\section{Discussion}

The present study demonstrates that in vitro treatment of proliferated healthy human mononuclear cells with MTX yields a significant apoptotic effect, a phenomenon that was first noticed by the Genestier group (Genestier et al., 1998). These studies provide substantial evidence of the beneficial effects of a low weekly dose of MTX in RA patients (Morgan et al., 1990; Leeb et al., 1990) who are characterized by the hyperproliferation of CD4+ cells (Goronzy et al., 1994; Waase et al., 1996; Schmidt et al., 1996). The mechanism by which MTX stimulates suppression in RA patients is still debated (Chabner et al., 1985; Sperling et al., 1990; Fairbanks et al., 1999; Cronstein et al., 1991; Segal et al., 1989; Seitz et al., 1996; Hooper et al., 1999). In this study, we tried to establish an early change in fluorescence polarization mediated by MTX, which indicates an apoptotic effect and could serve as a simple model to predict MTX efficiency in a specific RA patient.

The PI exclusion test indicates that the more the healthy MNC are activated, the more noticeable is the suppression by MTX. In order to confirm the above observation, we checked our model with flow cytometry. We specifically identified the apoptotic cells at the pre-G1 phase of the cell cycle. Here again, the significant suppression effect of MTX was observed only when healthy MNC were activated by PHA for $72 \mathrm{~h}$. The annexin V assay supports the above data in proving the fact that the apoptotic signal is more noticeable in activated lymphocytes suppressed by MTX. In the report by Genestier et al., MTX had been shown to exert an apoptotic effect after $8 \mathrm{~h}$ of exposure to MNC, which were then activated by different stimuli in a drug-free medium for $24 \mathrm{~h}$ (Genestier et al., 1998). In our model, we contend that stimulation of lymphocytes should be first followed by suppression by MTX - a condition typically found in RA patients.

The present study reports that MTX induces, in a timedependent manner, the best apoptotic effect at $72 \mathrm{~h}$ for hyperblasting lymphocytes, which have been morphologically viewed under a fluorescence microscope (data not shown). This hyperblasting formation of lymphocytes has been commonly reported to be one of the features of RA patients, at various stages of the disease (Harris, 1990; Stamenkovic et al., 1988; Feigenbaum et al., 1979).

The progressive increase in apoptotic cells after the prolonged incubation period $(72 \mathrm{~h})$ was noticeable mostly in MTX administration ranging from 0.1 to $1 \mu \mathrm{M}$ MTX. This model provides evidence for the immunosuppressive activity of low dose MTX, which is clinically effective in RA patients. Moreover, this in vitro model can serve as a tool for optimizing dosage and timing of low dose MTX administration for RA patients.

In order to advance and assess our model, we utilized our past experience with the advantages of the IC-S cytometer (Zurgil et al., 2000; Zurgil et al., 1999a; Deutsch et al., 2000a; Sunray et al., 1999; Deutsch et al., 2000b). Previous experiments with individual lymphocytes enabled the identification of lymphocyte activation by FDA fluorescence depolarization, as well as identification of early apoptotic events by FDA hyperpolarization (Cercek et al., 1978). Based on the above, we were interested in examining our model, where effective apoptosis is achieved for lengthy lymphocyte activation. Upon examining the apoptotic signals induced after $24 \mathrm{~h}$ of MTX administration, in conjunction with the previously described model, an intermediate FP value was revealed, reflecting the conflicting message(s) transported to the nuclei. FP levels reflect the rotational mobility level of the fluorescent molecule. FP measurement provides insight into the nature of macromolecular interactions, ligand binding, and conformational dynamics (Carrero et al., 1996; Thevenin et al., 1994), as well as intracellular protein processing (Weaver et al., 1997).

MNC activated for $96 \mathrm{~h}$ with PHA alone yielded the previously described characteristic behavior of activated lymphocytes. MNC that were activated with PHA for $72 \mathrm{~h}$ and then exposed to $1 \mu \mathrm{M}$ MTX for $24 \mathrm{~h}$ yielded a hyperpolarization signal typical of the apoptotic process, but atypical for PI observations where MTX alone barely enhanced the pre-G1 phase. Since PI exclusion and FDA polarization tests reflect two different properties related to the apoptotic reaction, it is assumed that the two assays should be analyzed on the basis of the stages involved in the apoptotic process. Early changes involved in the apoptotic process include cell dehydration and shrinkage, both of which were reported as having been identified by fluorescein 
hyperpolarization (Darzynkiewicz et al., 1997). On the other hand, the commonly used PI assay monitors cells according to their DNA content, in addition to their size, and analyzes the late parameters of cell death (Cohen, 1993). Based on the above, the effect of MTX administration on activated MNC was examined during the first minutes and hours of stimulation via FP measurement. The change in FDA FP is most significant during the second hour of suppression with MTX, while the third hour of suppression revealed a smaller change in FP, which decreases with time and is evident up to $24 \mathrm{~h}$ (Zurgil et al., 2000).

Final experiments using MNC derived from long-standing RA patients indicate that the IC-S apparatus recognizes disease progression and predicts MTX efficiency by measuring FP. All six RA patients who were clinically identified as progressive exhibited low FP values, which correlated with the activation signal that was artificially created in our model using PHA. Moreover, in vitro addition of MTX significantly increased their FP, a pattern which characterizes the apoptotic signal. We assume that the MTX dosage (10$12.5 \mathrm{mg} /$ week) clinically given to these patients has not achieved its complete efficiency and a higher dose (12.5-25 $\mathrm{mg} /$ week) should be considered. Interestingly, clinical data obtained from these patients did not show any significant improvement (including the patient's overall evaluation and the number of tender and swollen joints) during the period of six months following the start of treatment.

FP values obtained from diagnosed but untreated RA patients yielded a high FP value similar to that of the normal $\mathrm{MNC}$, described previously in the in vitro model. The further the disease progresses, the more activated the lymphocytes become, thereby enabling possible recognition by their low FP activation value. In vitro incubation of these RA lymphocytes with PHA followed by MTX significantly decreased the FP value in four of the five patients, indicating that MTX treatment could be the appropriate treatment for those four patients. The remaining patient should consider other therapeutic options. The MNC, treated in vitro by PHA alone, show a decrease in FP, indicative of their ability to be further activated. In vitro addition of MTX alone did not affect the MNC, a phenomenon explained by the effectiveness of MTX in activated lymphocytes. Another possible explanation could be MTX's increased effectiveness after prolonged treatment (Wolfe et al., 1990; Weinblatt et al., 1985).

This study may greatly benefit RA patients who are still undecided about pursuing MTX treatment. Our ability to trace and quickly predict MTX immunosuppression using our model should definitely be a great advantage for RA patients. In the future, we hope to focus on utilizing and adjusting this model for other DMARD (disease modifying anti-rheumatic drug) options to improve the treatment and provide optimal care for these patients.

Acknowledgments. This research was supported by the Horowitz Founda- tion and the Yael Research Fund.

\section{References}

Arnett, F.C., Edworthy, S.M., Bloch, D.A., McShane, D.J., Fries, J.F., Cooper, N.S., Healey, L.A., Kaplan, S.R., Liang, M.H., and Luthra, H.S. 1988. The American Rheumatism Association 1987 revised criteria for the classification of rheumatoid arthritis. Arthritis Rheum., 31: 315-324.

Carrero, J., Mallender, W.D., and Voss, E.W. Jr. 1996. Anti-metatype antibody stabilization of Fv 4-4-20 variable domain dynamics. J. Biol. Chem., 271: 11247-11252.

Cercek, L. and Cercek, B. 1977. Application of the phenomenon of changes in the structuredness of cytoplasmic matrix (SCM) in the diagnosis of malignant disorders. Europ J. Cancer, 13: 903-915.

Cercek, L., Cercek, B., and Ockey, C.H. 1978. Fluorescein excitation and emission polarization spectra in living cells: changes during the cell cycle. Biophys. J., 23: 395-405.

Chabner, P.A., Allegra, C.J., Curt, G.A., Clendeninn, N.J., Baram, J., Koisumi, S., Drake, J.C., and Joliver, J. 1985. Polyglutamation of methotrexate. Is methotrexate a prodrug? J. Clin. Invest., 76: 907-912.

Cohen, J.J. 1993. Apoptosis. Immunol. Today, 14: 126-130.

Cronstein, B.N., Eberle, M.A., Gruber, H.E., and Levin, R.I. 1991. Methotrexate inhibits neutrophil function by stimulating adenosine release from connective tissue cells. Proc. Natl. Acad. Sci. USA, 88: 2441-2445.

Cronstein, B.N., Naime, D., and Ostad, E. 1993. The antiinflammatory mechanism of methotrexate. Increased adenosine release at inflamed sites diminishes leukocyte accumulation in an in vivo model of inflammation. J.Clin. Invest., 92: 2675-2682.

Dandliker, W.B. and Feigen, G.A. 1961. Quantification of the antigenantibody reaction by the polarization of fluorescence. Biochem. Biophys. Res. Commun., 5: 299-305.

Darzynkiewicz, Z., Juan, G., Li, X., Gorczyca, W., Murakami, T., and Tragnos, F. 1997. Cytometry in cell necrobiology: analysis of apoptosis and accidental cell death (necrosis). Cytometry, 27: 1-20.

Deutsch, M. and Weinreb, A. 1994. Apparatus for high precision repetitive sequential optical measurement of living cells. Cytometry, 16: 214-227.

Deutsch, M., Zurgil, N., Kaufman, M., and Shapiro, H. 2000a. Analysis of enzyme kinetics in individual living cells utilizing fluorescence intensity and polarization measurements. Cytometry, 39: 36-44.

Deutsch, M., Zurgil, N., Kaufman, M., and Berke, G. 2000b. Fluorescence of polarization as an early measure of T-lymphocyte stimulation. In Methods in Molecular Biology, 134, T Cell Protocols: Development and Activation (Kearse, K.P., ed.). Humana Press, Inc., Totowa, NJ, pp. 221241.

Fairbanks, L.D., Ruckemann, K., Qiu, Y., Hawrylowicz, C.M., Richards, D.F., Swaminathan, R., Kirschbaum, B., and Simmonds, H.A. 1999. Methotrexate inhibits the first committed step of purine biosynthesis in mitogen-stimulated human T-lymphocytes; a metabolic basis for efficacy in rheumatoid arthritis. Biochem. J., 342: 143-152.

Feigenbaum, S.L., Masi, A.T., and Kaplan, S.B. 1979. Prognosis in rheumatoid arthritis. A longitudinal study of newly diagnosed younger adult patients. Am. J. Med., 66: 377-384.

Genestier, L., Paillot, R., Fournel, S., Ferraro, C., Miossec, P., and Revillard, J.P. 1998. Immunosuppressive properties of methotrexate: apoptosis and clonal deletion of activated peripheral T cells. J. Clin. Invest., 102: 322-328.

Gidwani, A., Holowka, D., and Baird, B. 2001. Fluorescence anisotropy measurements of lipid order in plasma membranes and lipid rafts from RBL-2H3 mast cells. Biochemistry, 40: 12422-12429.

Goronzy, J.J., Bazzanella, P., Hu, W., Jendro, M.C., Walser-Kuntz, D.R., and Weyand, C.M. 1994. Dominant clonotypes in the repertoire of peripheral $\mathrm{CD}^{+} \mathrm{T}$ cells in rheumatoid arthritis. J. Clin. Invest., 94: 
2068-2076

Harris, E.D., Jr. 1990. Rheumatoid arthritis. Pathophysiology and implication for therapy. N. Engl. J. Med., 322: 1277-1289.

Hooper, M., Kallas, E.G., Coffin, D., Campbell, D., Evans, T.G., and Looney, R.J. 1999. Cytomegalovirus seropositivity is associated with the expansion of $\mathrm{CD}^{+} \mathrm{CD} 28^{-}$and $\mathrm{CD}^{+} \mathrm{CD} 28^{-} \mathrm{T}$ cells in rheumatoid arthritis. J. Rheumatol., 26: 1452-1457.

Infante-Duarte, C. and Kamradt, T. 1999. Th1/Th2 balance in infection. Springer Seminars in Immunopathology, 21: 317-338.

Jackson, R.C., Fry, D.W., Boritzki, T.J., Besserer, J.A., Leopold, W.R., Sloan, B.J., and Elslager, E.F. 1984. Biochemical pharmacology of the lipophilic antifolate, trimetrexate. Adv. Enzyme Regul., 22: 187-206.

Jolley, M.E. 1996. Fluorescence polarization assays for the detection of proteases and their inhibitors. J. Biomolecular Screening, 1: 33-38.

Kaplan, M.R., Trubniykov, E., and Berke, G. 1997. Fluorescence depolarization as an early measure of lymphocyte stimulation. J. Immunol. Meth., 201: 15-24.

Kusaba, M., Honda, J., Fukuda, T., and Oizumi, K. 1998. Analysis of type 1 and type $2 \mathrm{~T}$ cells in synovial fluid and peripheral blood of patients with rheumatoid arthritis. J. Rheumatol., 25: 1466-1471.

Leeb, B., Ogris, E., Dunky, A., and Mutzik, O. 1990. Pharmacokinetics of methotrexate in rheumatoid arthritis and psoriatic arthritis. Arthritis. Rheum., 30: A121.

Levison, S.A., Dandliker, W.B., Brawn, R.J., and Vanderlan, W.P. 1976. Fluorescence polarization immunoassay: theory and experimental method. Endocrinology, 99: 1129-1143.

Morabito, L., Montesinos, M.C., Schreibman, D.M., Balter, L., Thompson, L.F., Resta, R., Carlin, G., Huie, M.A., and Cronstein, B.N. 1998. Methotrexate and sulfasalazine promote adenosine release by a mechanism that requires ecto-5'-nucleotidase-mediated conversion of adenine nucleotides. J. Clin. Invest., 101: 295-300.

Morgan, S.L., Baggott, J.E., Vaughn, W.H., Young, P.K., Austin, J.V., Krumdieck, C.L., and Alarcon, G.S. 1990. The effect of folic acid supplementation on the toxicity of low-dose methotrexate in patients with rheumatoid arthritis. Arthritis. Rheum., 33: 9-18.

Nishioka, K., Hasunuma, T., Kato, T., Sumida, T., and Kobata, T. 1998. Apoptosis in rheumatoid arthritis: a novel pathway in the regulation of synovial tissue. Arthritis Rheum., 41: 1-9.

Orjasaeter, H., Hordfald, G., and Svendsen, I. 1979. Response of Tlymphocoytes to phytohaemagglutinin (PHA) and to cancer-tissueassociated antigens, measured by the intracellular fluorescence polarization techniques (SCM test). Br. J. Cancer, 40: 628-633.

Pritchard, J.A.V., Sutherland, W.J., Siddall, J.E., Bater, A.J., Kerby, I.J., Deeley, T.J., Griffity, G, Sinclair, R., Davies, B.H., Rimmer, A., and Webster, D.J.T. 1982. A clinical assessment of fluorescence polarization changes in lymphocytes stimulated by phytohaemagglutinin (PHA) in malignant and benign diseases. Eur. J. Cancer Clin. Oncol., 18: 651659.

Rolland, J.M., Nairn, R.C., Nind, A.P., and Pihl, E. 1984. Significance of lymphocyte fluorescence polarization changes after phytohaemagglutinin stimulation in cancer and non-cancer conditions. JNCI, 72: 267-274.

Rudwaleit, M., Yin, Z., Siegert, S, Grolms, M., Radbruch, A., Braun, J., and Sieper, J. 2000. Response to methotrexate in early rheumatoid arthritis is associated with a decrease of $\mathrm{T}$ cell derived tumour necrosis factor É $\varnothing$, increase of interleukin 10, and predicted by the initial concentration of interleukin 4. Annals of the Rheumatic Diseases, 59: 311-314.

Sakamoto, S., Maida, H., Yamasaki, K., Aikawa, S., and Hinuma, Y. 1981. Evaluation of cellular fluidity of peripheral blood lymphocytes from patients with urogenital cancers by fluorescence polarization technique: PHA response and prognosis. Eur. J. Cancer Clin. Oncol., 17: 10551115 .

Schmidt, D., Goronzy, J.J., and Weyand, C.M. 1996. CD4 ${ }^{+} \mathrm{CD}_{7}^{-} \mathrm{CD}_{28}{ }^{-} \mathrm{T}$ cells are expanded in rheumatoid arthritis and are characterized by autoreactivity. J. Clinical Invest., 97: 2027-2037.

Schnuda, N.D. 1980. Evaluation of fluorescence polarization of human blood lymphocytes (SCM test) in the diagnosis of cancer. Cancer, 46: 1164-1173.

Schuerwegh, A.G., van Offel, J.F., Bridts, C.H., Stevens, W.J., De Clerck, L.S. 2001. Influence of longterm therapy with methotrexate and low dose corticosteroids on type 1 and type 2 cytokine production in CD4 ${ }^{+}$ and $\mathrm{CD}^{+} \mathrm{T}$ lymphocytes of patients with rheumatoid arthritis. $J$. Rheum., 28: 1793-1799.

Segal, R., Mozes, E., Yaron, M., and Tartakovsky, B. 1989. The effects of methotrexate on the production and activity of interleukin-1. Arthritis Rheum., 32: 370-377.

Seitz, M., Loetscher, P., Dewald, B., Towbin, H., Rordorf, C., Gallati, H., and Gerber, N. 1996. Interleukin 1 (IL-1) receptor antagonist, soluble tumor necrosis factor receptors IL-1 beta, and IL-8-markers of remission in rheumatoid arthritis during treatment with methotrexate. J. Rheum., 23: $1512-1516$.

Shapiro, H.M. Practical Flow Cytometry. 1995. 3rd ed., Wiley-Liss, New York.

Singh, V.K, Mehrotra, S., and Agarwal, S.S. 1999. The paradigm of Th1 and Th2 cytokines. Its relevance to autoimmunity and allergy. Immunologic Research, 20: 147-161.

Sperling, A., Benimeno, I., Arsten, K.F., Anderson, R., Colbyn, I., and Weinblatt, M.E. 1990. Effects of methotrexate therapy on 5-lipoxygenase pathway metabolism of arachidonic acid in rheumatoid arthritis. Arthritis. Rheum., 33: 173.

Stamenkovic, I., Stegagno, M., Wright, K.A., Krane, S.M., Amento, E.P., Colvin, R.B., Duquesnoy, R.J., and Kurnick, J.T. 1988. Clonal dominance among T-lymphocyte infiltrates in arthritis. Proc. Natl. Acad. Sci. USA, 85: 1179-1183.

Sunray, M., Kaufman. M., Zurgil, N., and Deutsch, M. 1999. The trace and subgrouping of lymphocyte activation by dynamic fluorescence intensity and polarization measurements. Biochem. Biophys. Res. Comm., 261: 712-719.

Thevenin, B.J., Periasamy, N., Shohet, S.B., and Verkman, A.S. 1994. Segmental dynamics of the cytoplasmic domain of erythrocyte band 3 determined by time-resolved fluorescence anisotropy: sensitivity to $\mathrm{pH}$ and ligand binding. Proc. Natl. Acad. Sci. USA, 91: 1741-1745.

Waase, I., Kayser, C., Carlson, P.J., Goronzy, J.J., and Weyand, C.M. 1996. Oligoclonal $\mathrm{T}$ cell proliferation in patients with rheumatoid arthritis and their unaffected siblings. Art. Rheum., 39: 904-913.

Weaver, D.J. Jr., Durack, G., and Voss, E.V., Jr. 1997. Analysis of the intracellular processing of proteins: application of fluorescence polarization and a novel fluorescent probe. Cytometry, 28: 25-35.

Weinblatt, M.E., Coblyn, J.S., Fox, D.A., Fraser, P.A., Holdsworth, D.E., Glass, D.N., and Trentham, D.E. 1985. Efficacy of low dose methotrexate in rheumatoid arthritis. N. Engl. J. Med., 312: 818-822.

Willkens, R.F., Williams, H.J., Ward, J.R., et al. 1984. Randomized double blind placebo controlled trial of low dose pulse methotrexate in psoriatic arthritis. Arthritis Rheum., 27: 376-381.

Wolfe, F., Hawley, D.J., and Cathey, M.A. 1990. Termination of slow acting antirheumatic therapy in rheumatoid arthritis: a 14-year prospective evaluation of 1017 consecutive starts. J. Rheumatol., 17: 994-1002.

Zurgil, N., Gerbat, S., Langevitz, P., Tishler, M., Ehrenfeld, M., Kaufman, M., Deutsch, M., and Shoenfeld, Y. 1999a. Detection of cellular activity in autoimmune disorders by the Cellscan system. In The Decade of Autoimmunity (Shoenfeld H. ed.). Elsevier Science, B.V., pp. 295-304.

Zurgil, N., Kaufman, M., Solodiev, I., and Deutsch, M. 1999b. Determination of cellular thiol levels in individual viable lymphocytes by means of fluorescence intensity and polarization. J. Immunol. Methods, 229: 2334.

Zurgil, N., Schiffer, Z., Shafran, Y., Kaufman, M., and Deutsch, M. 2000. 
S. Herman et al.

Fluorescein fluorescence hyperpolarization as an early kinetic measure of the apoptotic process. Biochem. Biophys. Res. Comm., 268: 155-163.
(Received for publication, November 21, 2002

and accepted, February 19, 2003) 